\title{
Study on Cultivation of Intercultural Communication Competence of College English Based on Modern Information Technology
}

\author{
https://doi.org/10.3991/ijet.v13i09.8724 \\ Bingzhuan Peng \\ Harbin University of Science and Technology, Harbin, China \\ pengbingzhuan $163 . \mathrm{com}$
}

\begin{abstract}
Economic globalization, integration of the world, and wide application and advanced development of modern information technology (MIT) demand high requirements for talents. Traditional teaching methods and means cannot satisfy the requirements of students for real language communication environment and language output. Consequently, students exhibit low intercultural communication ability and fail to satisfy the ultimate goal of foreign language teaching. A novel method to cultivate students' intercultural communication competence (ICC) in college English based on MIT was proposed in this study. The method was used to examine students' intercultural sensitivity (IS) and ICC. The concept of ICC was redefined. A model of ICC in college English based on MIT and a teaching mode for cultivating students' ICC in college English based on MIT were constructed. The proposed teaching mode was applied to a teaching experiment, and interviews and questionnaires were used to estimate students' IS and ICC. Results demonstrate that this mode is superior to traditional teaching methods, surpasses the limitations of time and space, realizes global information sharing, and integrates the language and cultural learning among students organically. The constructed teaching mode meets the needs and demands of most students and provides a resource-rich learning platform where students can improve their IS and ICC.
\end{abstract}

Keywords-modern information technology, college English, intercultural communication competence, empirical study

\section{Introduction}

People have entered an era of unprecedented electronic information age with the extensive application and advanced development of economic globalization, integration of the world, and modern information technology (MIT). This phenomenon has increased the demand for highly qualified talents with skilled foreign language communication competence and thus has raised requirements for talent cultivation. The ultimate goal of foreign language teaching in China is to cultivate students' intercultural communication competence (ICC), that is, the competence in the practical application of language. "New media not only influence the form and content of infor- 
mation or messages but also affect the perception of people about one another in the process of human communication, especially for individuals from different cultural or ethnic groups" [1]. In China, intercultural communication has been categorized as an explicit content of the English syllabus for English and non-English majors. Accordingly, cultivating ICC has begun to receive extensive attention from foreign language circles. However, most teachings and studies that concern the cultivation of ICC in China are studies on micro-level problems at the theoretical level. Therefore, the practical application of ICC must be investigated.

The use of MIT has penetrated all aspects of life, work, and learning of teachers and students, which has provided teachers and students with new technical forms and approaches to acquire and disseminate intercultural knowledge and information and can supplement insufficient traditional teaching methods effectively. Several related explorations indicate that MIT demonstrates a positive and active role in cultivating students' ICC. The present study explores a teaching mode for cultivating students' ICC in college English based on MIT and conducts an empirical study based on the aforementioned analysis.

\section{State of art}

Deardorff [2] defined ICC as the ability to empower individuals to be effective and communicative in intercultural contexts based on the intercultural knowledge, skills, and attitudes of an individual. Johnson [3] assumed that the concept of intercultural competence covered a wide range of fields. The relevant discussion in the American academic community was due to the social requirements at that time, that is, the diversity of American workplace employees and the continued exploration of American scholars on intercultural communication. However, ICC and intercultural competence in the above concepts have no distinction.

Lazar [4] asserted that "rapid and important relations have developed between intercultural communication and social media with globalization." Belz J [5] presented a detailed case study for developing intercultural competence to the investigation of evaluative language from a Hallidayian-inspired linguistic approach. However, the results of the study are non-universal because the study was based on a GermanAmerican e-mail. Steven L. Thorne and Rebecca W. Black [6] advocated to conduct exploration experiment of intercultural teaching by utilizing massive multiplayer online games (MMOs) and presented the application strategies of these MMOs; however, applying this method is limited in China. Robert J. Blake [7] proposed a real-time communicative teaching model, including the determination of communication topic, networking with communicative objects, implementation of communication based on the topic, and cultural analysis and summarization. However, the discussion of Blake lacks the analysis of teaching effects.

Gaoda He [8] emphasized that "multimedia technology broadens intercultural communication media, diversifies the models and types of intercultural communication, expands the functions of intercultural communication, and reduces the barriers to intercultural communication gradually." This author focused on the theoretical aspect 
of multimedia technology on intercultural communication, but ignored the empirical study of multimedia technology on intercultural communication. Kun Dai [9] presented the novel concept of "virtual training environment to immensely cultivate intercultural competence" supported by virtual reality technology. However, Dai focused more on the theory than the analysis of teaching effect. Xiaofeng Wang and Xuhuan Xiao [10] analyzed the characteristics and advantages of multimedia network teaching methods in teaching; Wang and Xiao explained that, in college English teaching, teachers should not only pay attention to the listening, speaking, reading, writing, and translation skills of students but also make full use of the advantages of the network and strive to cultivate the sensitivity of students to cultural differences and foster students' ICC. However, their work only emphasized the theory and did not perform any practical experiment. Yu Guo [11] expounded the application of WebQuest mode in developing ICC, but Guo only concentrated on the WebQuest mode and did not cover other aspects of MIT. Wenzhong Hu [12] emphasized that "a weakness of the intercultural communication survey in China is the lack of empirical study". Hu also requested scholars in intercultural communication to vigorously strengthen the empirical study in China.

The present study redefines the concept of ICC, proposes a model of ICC in college English based on MIT and a teaching mode for cultivating students' ICC in college English based on MIT, and conducts an empirical study. This teaching mode not only improves students' ICC but also enriches the empirical study of ICC. This mode enables teachers to improve the teaching quality and efficiency and understand the cultivation of students' ICC effectively in China.

The remainder of this study is organized as follows. Section 3 redefines ICC, constructs a model of ICC in college English based on MIT and a novel teaching mode for cultivating students' ICC in college English based on MIT. Section 4 discusses the empirical study of cultivating ICC in college English based on MIT using the mode. Section 5 summarizes the conclusions.

\section{$3 \quad$ Methodology}

\subsection{Redefinition of the concept of ICC}

In this study, the concept of ICC was redefined as the competence of language users in using a foreign language to communicate with people from different cultural backgrounds, including three aspects, namely, the skills, attitudes, and knowledge of language users. In particular, knowledge is divided into intercultural knowledge and communicative knowledge. Skills are divided into language skills and social communicative skills. Attitudes include the attitude toward national culture and attitude toward non-national cultures. 


\subsection{Construction of the ICC model in college English based on MIT}

In accordance with the ICC model by Byram (1997) (Fig. 1) and cross-cultural communicative competence model by Qiufang Wen (1999) (Fig. 2) [13], a model for ICC in college English based on MIT was constructed (Fig. 3).

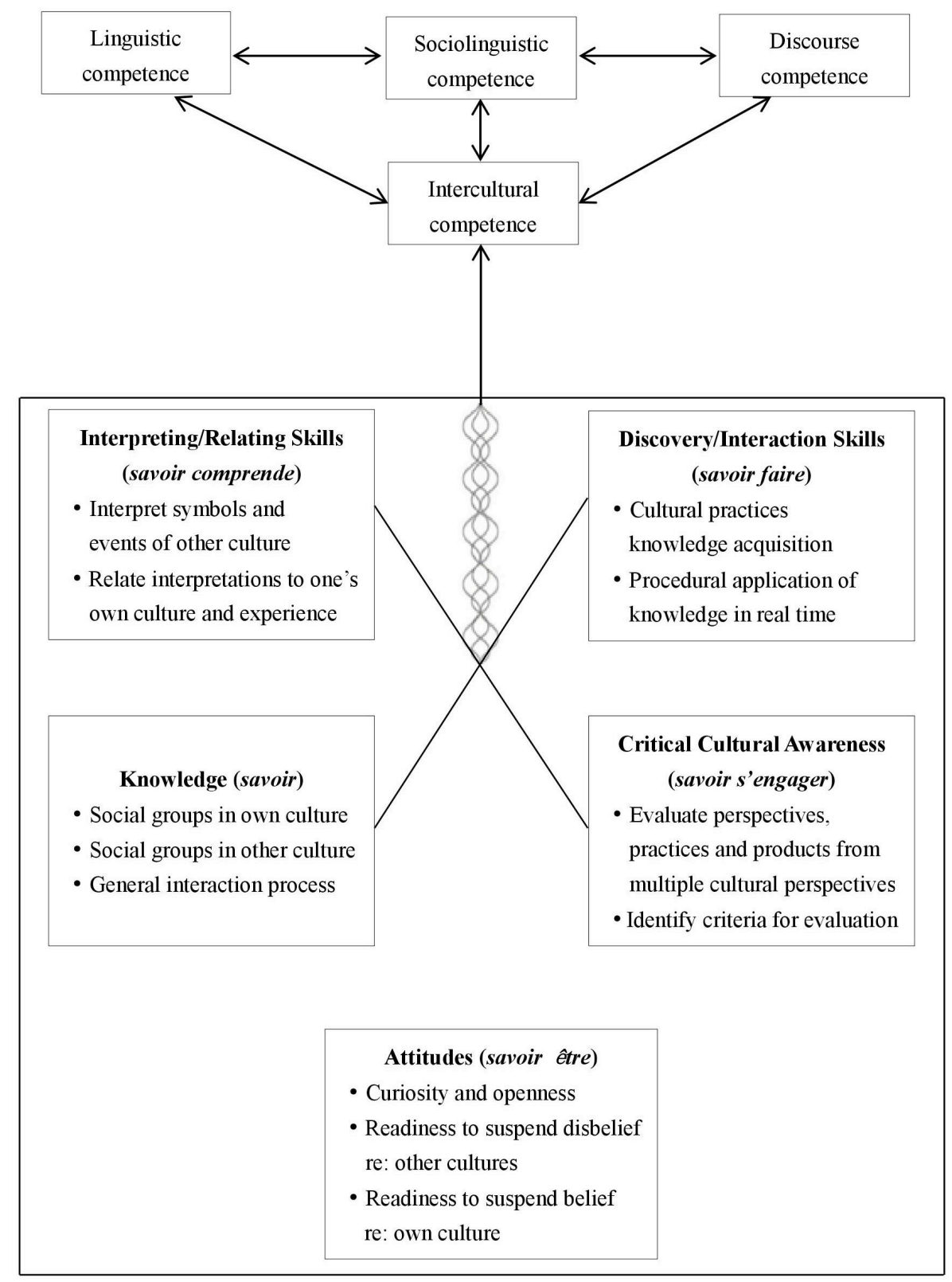

Fig. 1. ICC model by Byram (1997) 


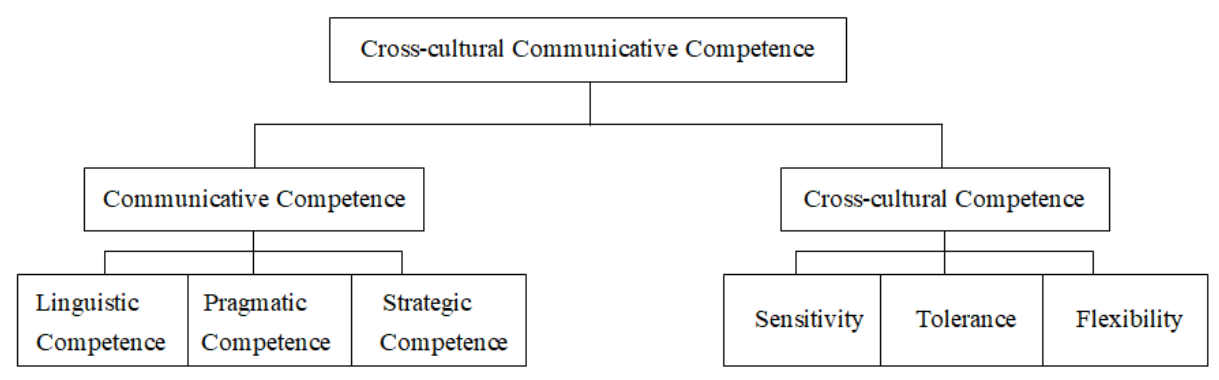

Fig. 2. Cross-cultural communicative competence model by Qiufang Wen (1999)

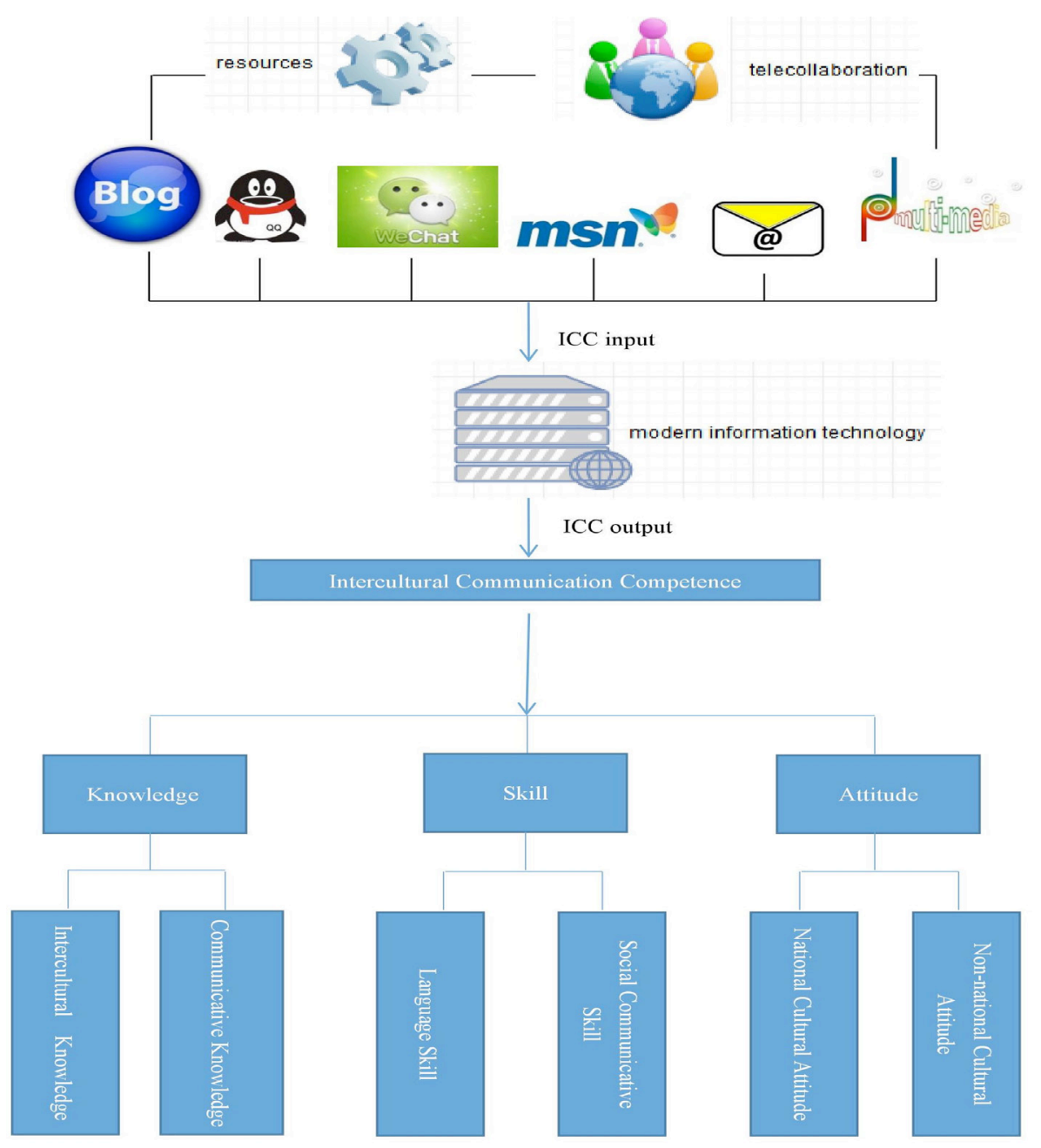

Fig. 3. ICC Model in college English based on MIT 
In this model, teachers can use MIT online or offline to provide learners with rich resources and opportunities for remote collaboration to input ICC and share resources and learning activities. Teachers can access data-based courseware, micro-curriculum, teaching resources, homework assignments, and homework quizzes without restrictions on time, space, and locations. Simultaneously, teachers can use MIT to monitor the learning activities and keep abreast of self-learning among students. Thus, teachers can make teaching more targeted and improve teaching effectiveness.

Students can also use MIT to access information, finish their homework, conduct discussions, self-learning, and collaborative learning, and achieve student-student and student-teacher interactions without restrictions on time, space, and locations. Furthermore, students can obtain other opportunities to utilize online interactive platforms, such as QQ, WeChat, Skype, MSN, and other interactive software, blogs, and e-mails to output ICC, that is, to develop intercultural communication with learners of different cultural backgrounds. Learners of different cultural backgrounds can enhance their understanding of the Chinese and Western cultural knowledge and their understanding of the similarities and differences between Chinese and Western cultures through mutual cooperation. Students can also select to study the contents of intercultural communication independently, plan their own intercultural communication learning progress, learn about intercultural communication knowledge and skills independently, and freely explore and perceive different cultures, thereby enhancing their intercultural sensitivity (IS) and ICC.

This study points out that the development of ICC is a dynamic process (Fig. 4). In particular, developing ICC is a changing process from concrete, superficial, and partial knowledge of cultures to abstract, thorough, and general knowledge of cultures, and from imperfect, unversed, and inefficient skills to complete, versed, and efficient skills, and from the attitude toward national culture to the attitude toward non-national cultures.

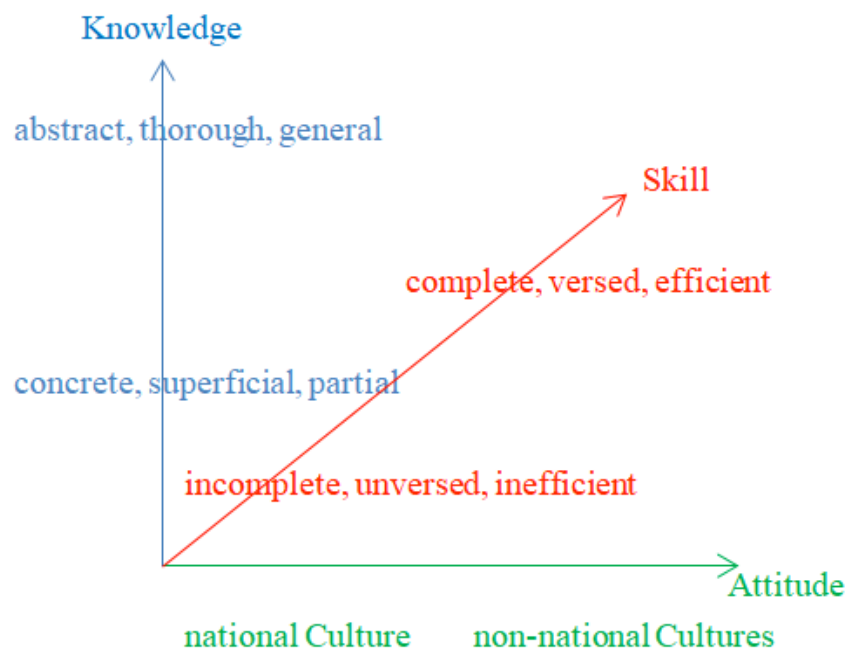

Fig. 4. Diagram of the dynamic development of ICC 


\subsection{Construction of the teaching mode for cultivating students' ICC in college English based on MIT}

Based on the above model of ICC in college English based on MIT, a teaching mode for cultivating students' ICC in college English based on MIT was constructed. In the teaching mode, teachers will select intercultural teaching resources, determine the theme of intercultural communication, integrate MIT into teaching ICC, enhance the application of a realistic technology in cultural teaching, build a WeChat platform, and create situations of intercultural communication. Moreover, teachers will implement situational teaching, virtual reality, and game-teaching methods, organically combine language teaching with cultural teaching, and receive feedback on intercultural communication. Teachers will also enable students to engage in ubiquitous learning, collaborative learning, and mobile learning with classmates, teachers, or foreign friends to solve problems that arise in intercultural communication.

\section{$4 \quad$ Result analysis and discussion}

\subsection{Subjects of the experiment}

The subjects of this experiment were sophomores at Harbin University of Science and Technology. The experimental group consisted of 124 students in Class 16-A2 (major in Mechanics), Class 16-B4 (major in Computer Science), and Class 16-C1 (major in Measurement). For the reliability of the experiment, the control group selected 124 students from Class 16-A1 (major in Mechanics), Class 16-B3 (major in Computer Science), and Class 16-C2 (major in Measurement). The teaching mode for cultivating students' ICC in college English based on MIT was used on the subjects to conduct a teaching experiment for one semester.

\subsection{Procedure}

This experiment adopted interviews to investigate the satisfaction of students with college English courses and used pre-experimental questionnaires and postexperimental questionnaires to examine students' IS and ICC. Each questionnaire consisted of two parts. The IS scale (ISS) compiled by Chen and Starosta was used in the first part of the questionnaire. This scale included 24 five-point scales, which measured the variables that made up the five levels of IS, and the total score was 120 points [14]. These five variables were interaction engagement, respect for cultural differences, interaction confidence, interaction enjoyment, and interaction attentiveness [15]. The second part was an ICC test designed on the basis of the skills, attitudes, and knowledge of language users. This part consisted of 40 questions, and the total score was 100 points. The test of knowledge was divided into intercultural knowledge and communicative knowledge, the test of skills was divided into language skills and social communicative skills and the test of attitudes was divided into the attitude toward national culture and attitude toward non-national cultures. 


\subsection{Procedure Teaching effect}

The data of the experimental and control groups were collected and inputted into the Excel and SPSS19.0 software after the teaching experiment for a semester. The analysis results are as follows:

Table 1. Students' degree of satisfaction with the college English courses of the Experimental Group and Control Group

\begin{tabular}{|l|c|c|c|c|c|c|c|c|c|c|}
\hline & \multicolumn{2}{|c|}{ Very satisfied } & \multicolumn{2}{|c|}{ Quite satisfied } & \multicolumn{2}{c|}{$\begin{array}{c}\text { Generally } \\
\text { satisfied }\end{array}$} & \multicolumn{2}{c|}{$\begin{array}{c}\text { Not very } \\
\text { satisfied }\end{array}$} & \multicolumn{2}{c|}{ Not satisfied } \\
\cline { 2 - 11 } & $\boldsymbol{N}$ & $\begin{array}{c}\text { percentage } \\
(\%)\end{array}$ & $\boldsymbol{N}$ & $\begin{array}{c}\text { percentage } \\
(\%)\end{array}$ & $\boldsymbol{N}$ & $\begin{array}{c}\text { percentage } \\
(\%)\end{array}$ & $\boldsymbol{N}$ & $\begin{array}{c}\text { percentage } \\
(\%)\end{array}$ & $\boldsymbol{N}$ & $\begin{array}{c}\text { percentage } \\
(\%)\end{array}$ \\
\hline Control Group & 24 & 19.35 & 46 & 37.10 & 43 & 34.68 & 7 & 5.65 & 4 & 3.23 \\
\hline $\begin{array}{l}\text { Experimental } \\
\text { Group }\end{array}$ & 43 & 34.68 & 61 & 49.19 & 15 & 12.10 & 3 & 2.42 & 2 & 1.61 \\
\hline
\end{tabular}

Table 1 summarized the degree of satisfaction of students with the college English courses of the experimental and control groups. In the experimental group, 104 students were very and relatively satisfied with the college English courses; this figure represented $83.87 \%$ of students and was significantly higher than that of the students with a similar response in the control group. Furthermore, only 20 of the students were generally satisfied, not very satisfied, and not satisfied with college English courses in the experimental group; this figure accounted for $16.13 \%$ of the students and was significantly lower than that of the students with a similar response in the control group. These results show that the teaching mode is helpful in improving the satisfaction of students with college English courses.

Table 2. Comparison of students' ISS of the Experimental Group and Control Group

\begin{tabular}{|c|c|c|c|c|c|c|c|}
\hline \multirow{2}{*}{ Total Scores } & \multicolumn{3}{|c|}{ Control Group } & \multicolumn{3}{c|}{ Experimental Group } & \multirow{2}{*}{ P } \\
\cline { 2 - 8 } & $\boldsymbol{N}$ & Percentage (\%) & $\boldsymbol{M}$ & $\boldsymbol{N}$ & Percentage (\%) & $\boldsymbol{M}$ & \\
\hline $111-120$ & 3 & 2.42 & 111.33 & 23 & 18.55 & 117.00 & 0.001 \\
\hline $101-110$ & 8 & 6.45 & 102.25 & 44 & 35.48 & 106.38 & 0.000 \\
\hline $91-100$ & 58 & 46.77 & 92.50 & 30 & 24.19 & 96.17 & 0.027 \\
\hline $81-90$ & 40 & 32.26 & 84.08 & 21 & 16.94 & 89.26 & 0.023 \\
\hline $71-80$ & 13 & 10.48 & 74.20 & 5 & 4.03 & 78.64 & 0.000 \\
\hline $61-70$ & 2 & 1.61 & 63.00 & 1 & 0.80 & 68.00 & 0.018 \\
\hline
\end{tabular}

Table 2 displayed the comparison results of students' IS in the experimental and control groups at the end of the semester. Students' IS was classified into three categories in this study. The first category was the high-level group with scores between 101 and 120, the second category was the medium-level group with scores between 81 and 100, and the third category was the low-level group with scores below 80 points. 
In Table 2, most of the students in the control group scored between 81 and 100, accounting for $79.03 \%$. Accordingly, the majority of students recorded a medium level of IS. Only 11 students had a high level of IS, with a total score of more than 100 , which represented $8.87 \%$. The number of students in the experimental group with more than 100 points was 67 , which comprised $54.03 \%$, after the experiment for one semester. That is, nearly half of the students reached a high level of IS after the teaching experiment. The number of each level of IS was significantly higher in the experimental group than in the control group, and the mean score of each level was also significantly higher in the experimental group than in the control group. The $\mathrm{P}$ values of the comparison of mean scores in each level were all less than 0.05 , which indicated significant differences in the scores of the control and experimental groups and confirmed that the teaching mode could improve students' IS effectively.

Table 3. Comparison of the five factors in ISS of the Experimental Group and Control Group

\begin{tabular}{|l|c|c|c|c|c|c|c|c|c|}
\hline \multicolumn{1}{|c|}{\begin{tabular}{c}
\multicolumn{1}{c}{ Five Factors } \\
in ISS
\end{tabular}} & \multicolumn{4}{|c|}{ Control Group } & \multicolumn{4}{c|}{ Experimental Group } & \multirow{2}{*}{ P } \\
\cline { 2 - 10 } & Max & Min & $\boldsymbol{M}$ & SD & Max & Min & M & SD & \\
\hline $\begin{array}{l}\text { interaction en- } \\
\text { gagement }\end{array}$ & 30 & 21 & 23.37 & 2.164 & 35 & 23 & 28.28 & 2.176 & 0.000 \\
\hline $\begin{array}{l}\text { respect for cultural } \\
\text { differences }\end{array}$ & 26 & 18 & 22.31 & 2.158 & 30 & 24 & 27.98 & 1.986 & 0.014 \\
\hline $\begin{array}{l}\text { interaction confi- } \\
\text { dence }\end{array}$ & 22 & 11 & 14.87 & 2.243 & 25 & 16 & 18.95 & 1.926 & 0.000 \\
\hline $\begin{array}{l}\text { interaction enjoy- } \\
\text { ment }\end{array}$ & 13 & 7 & 11.28 & 1.945 & 15 & 9 & 14.78 & 1.807 & 0.000 \\
\hline $\begin{array}{l}\text { interaction atten- } \\
\text { tiveness }\end{array}$ & 13 & 6 & 11.72 & 1.296 & 15 & 10 & 13.89 & 1.291 & 0.026 \\
\hline
\end{tabular}

Table 3 presented that the scores of the five factors of ISS were significantly higher in the experimental group than in the control group. The $\mathrm{P}$ values on the basis of interaction engagement, respect for cultural differences, interaction confidence, interaction enjoyment, and interaction attentiveness ware $0.000,0.014,0.000,0.000$, and 0.026 , respectively. Thus, all $\mathrm{P}$ values were less than 0.05 , which indicated the significant differences of the IS in the experimental and control groups. These significant differences proved that teaching mode was conducive to the improvement of students' IS.

Table 4. Comparison of students' ICC of the experimental group and control group at the beginning of the semester

\begin{tabular}{|c|c|c|c|c|c|c|c|c|c|c|}
\hline \multirow{2}{*}{} & \multirow{2}{*}{ N } & \multicolumn{4}{|c|}{ Control Group } & \multicolumn{4}{c|}{ Experimental Group } & \multirow{2}{*}{ P } \\
\cline { 2 - 11 } & & Max & Min & $\boldsymbol{M}$ & $\boldsymbol{S D}$ & $\boldsymbol{M a x}$ & $\boldsymbol{M}$ in & $\boldsymbol{M}$ & $\boldsymbol{S D}$ & \\
\hline ICC & 124 & \multirow{2}{*}{85} & 40 & 58.24 & 7.305 & 87 & 38 & 58.41 & 7.249 & 0.175 \\
\hline NVQ & 124 & & & & & & & & \\
\hline
\end{tabular}

NVQ: Number of valid questionnaires Total score: 100 
Table 4 indicated that the maximum, minimum, and mean scores of the experimental group at the beginning of the semester were nearly similar to those of the control group. The $\mathrm{P}$ value was 0.175 , which was more than 0.05 , showing no significant differences in the students' ICC between the experimental and the control groups.

Table 5. Comparison of students' ICC of the experimental group and control group at the end of the semester

\begin{tabular}{|c|c|c|c|c|c|c|c|c|c|c|}
\hline & \multirow{2}{*}{$\mathbf{N}$} & \multicolumn{4}{|c|}{ Control Group } & \multicolumn{4}{c|}{ Experimental Group } & \multirow{2}{*}{ P } \\
\cline { 3 - 10 } & & Max & Min & $\boldsymbol{M}$ & $\boldsymbol{S D}$ & $\boldsymbol{M a x}$ & $\operatorname{Min}$ & $\boldsymbol{M}$ & $\boldsymbol{S D}$ & \\
\hline ICC & 124 & \multirow{2}{*}{8} & 41 & 60.66 & 7.547 & 98 & 67 & 87.69 & 7.127 & \multirow{2}{*}{0.000} \\
\hline NVQ & 124 & & & & & &
\end{tabular}

Table 5 denoted that the maximum score of the ICC at the end of the semester was 10 points higher in the experimental group than in the control group; the minimum score of the ICC was 26 points higher in the experimental group than in the control group; and the mean score of the ICC was 27.03 points higher in the experimental group than in the control group. Moreover, the $\mathrm{P}$ value was 0.000 , which was less than 0.05 , confirming that the differences in the ICC between the experimental and control groups were significant. Thus, this teaching mode helps students improve their ICC.

\section{Conclusions}

To improve students' ICC, the concept of ICC was redefined and an ICC model of ICC in college English based on MIT and a teaching mode for cultivating students' ICC in college English based on MIT were constructed. An empirical study that used the constructed teaching mode was conducted to investigate students' IS and ICC through interviews and questionnaires. The following conclusions could be drawn:

1. The teaching mode plays a significant supporting role and improves the teaching effect, degree of recognition of the curriculum among students, and students' ICC.

2. The teaching mode overcomes the limitations of time and space, creates rich and real situations of intercultural communication, provides rich teaching and learning resources, effectively supplements in-class learning materials, effectively expands extra-curricular learning, and achieves mobile teaching and learning.

3. The teaching mode organically integrates the language learning and cultural learning of students and develops students' ICC and language communication skills. Students have become dynamic and active cultural knowledge builders instead of static and passive knowledge receivers.

4. The teaching mode satisfies the communication requirements of students for future work, improves their interest in learning, increases their cultural input, enhances their intercultural awareness and IS, and improves the language application and self-learning competencies of students. 
5. Students can achieve one-on-one, one-to-many, many-to-one, and many-to-many interactions between students and teachers or between students and students by group discussions in this mode, thereby enhancing the teacher-student and student-student interactions and promoting the effective process of personalized instruction.

The teaching mode in this study improves the students' IS and ICC. However, the students' ICC is influenced by many factors, and the mode is limited to considering the role of MIT in cultivating students' ICC. Therefore, other influencing factors should be considered in future studies.

\section{Acknowledgment}

This work was supported in part by China Scholorship Council, Foreign Language Education Academic Exchange Base Research Project of Heilongjiang Province in 2017 (project no.T2017002), the Philosophy and Social Sciences Research Planning Project of Heilongjiang Province in 2017 (project no. 17YYC150) and the Key Research Projects of Economic and Social Development of Heilongjiang Province in 2017 (Special Project of Foreign Languages) (project no. WY2017014-A).

\section{$7 \quad$ References}

[1] Guoming Chen. Impact of New Media on Intercultural Communication, China Media Research, 2012, vol.8 (2), pp. 1-10.

[2] Darla K. Deardorff. Identification and Assessment of Intercultural Competence as a Student Outcome of Internationalization, Journal of Studies in International Education, 2006, vol.10(3), pp. 241-266. https://doi.org/10.1177/1028315306287002

[3] James P. Johnson et al. Cross Cultural Competence in International Business, Journal of International Business Studies, 2006), vol. 37(4), pp. 525-543. https://doi.org/10.1057/ palgrave.jibs. 8400205

[4] Lazar, Ludmila. Media as a Mediator of Intercultural Communication in the Age of Globalization, International Journal of Communication Research, 2012, vol. 2(4), pp. 291-294.

[5] Belz, Julie A. Linguistic Perspectives on the Development of Intercultural Competence in Telecollaboration, Language Learning \& Technology, 2003, vol. 7(5), pp. 68-117.

[6] Steven L. Thorne \& Rebecca W. Black. Language and Literacy Development in Computer-mediated Contexts and Communities, Annual Review of Applied Linguistics, 2007, vol. 27(3), pp. 133-160.

[7] Robert J. Blake. New trends in using technology in the language curriculum, Annual Review of Applied Linguistics, 2007, vol. 27(3), pp. 76-97. https://doi.org/10.1017/ S0267190508070049

[8] Jijun Wang, \& Zhaokuan Meng. Survey of Information Technology Promoting Cultural Teaching from the Perspective of Integration, Modern Educational Technology, 2014, vol. 24(4), pp. 19-22.

[9] Kun Dai. Intercultural Communication Competence Cultivation Based on Metacognition in Immersive Virtual Cultural Environment, Journal of Xi'an University of Arch. \& Tech. (Social Science Edition), 2012, vol. 31(8), pp. 90-95. 
Paper-Study on Cultivation of Intercultural Communication Competence of College English Based ..

[10] Xiaofeng Wang, \& Xuhuan Xiao. Cultivation of Intercultural Communication Competence in Modern Multimedia Network Teaching Environment, Journal of Sichuan International Studies University, 2006, vol. 22(6), pp. 134-141.

[11] Yu Guo. Application of WebQuset in Development of Intercultural Communication Competence, Journal of Xuzhou Institute of Architectural Technology, 2009, vol. 9(4), pp. 9396.

[12] Wenzhong Hu. On the Empirical Study of Cross-cultural Communication, Foreign Language Teaching and Research, 2005, vol. 37(5), pp. 323-400.

[13] Hua Zhong, \& Weiwei Fan. The Theoretical Framework for the Construction of Measuring Tools for Cross-cultural Communication of Chinese College Students, Foreign Language Education in China, 2013, vol. 6(3), pp. 19-28.

[14] Chen, G. M., \& Starosta, W. J. The development and validation of the intercultural sensitivity scale. Human Communication, 2000, vol. 3(1), pp.1-14.

[15] Shiyong Peng. Cross-cultural Sensitivity: Comparison between English Majors and NonEnglish Majors, Journal of Ningxia University (Humanities \& Social Sciences Edition), 2007, vol. 29(1), pp. 171-176.

\section{Author}

Bingzhuan Peng is an associate professor in the School of Foreign Languages, Harbin University of Science and Technology, Harbin 150080, China (pengbingzhuan@163.com).

Article submitted 11 April 2018. Resubmitted 20 May 2018. Final acceptance 28 May 2018. Final version published as submitted by the author. 